\title{
Neural respiratory drive in healthy subjects and in COPD
}

\author{
C.J. Jolley*, Y-M. Luo\#, J. Steier*, C. Reilly*, J. Seymour*, A. Lunt*, K. Ward*, \\ G.F. Rafferty*, M.I. Polkey and J. Moxham*
}

ABSTRACT: The aim of the present study was to use the diaphragm electromyogram (EMGdi) to compare levels of neural respiratory drive (NRD) in a cohort of healthy subjects and chronic obstructive pulmonary disease (COPD) patients, and to investigate the relationship between NRD and pulmonary function in COPD.

EMGdi was recorded at rest and normalised to peak EMGdi recorded during maximum inspiratory manoeuvres (EMGdi \% max) in 100 healthy subjects and 30 patients with COPD, using a multipair oesophageal electrode. EMGdi was normalised to the amplitude of the diaphragm compound muscle action potential (CMAPdi,Ms) in 64 healthy subjects.

The mean \pm SD EMGdi \% max was $9.0 \pm 3.4 \%$ in healthy subjects and $27.9 \pm 9.9 \%$ in COPD patients, and correlated with percentage predicted forced expiratory volume in one second, vital capacity and inspiratory capacity in patients. EMGdi \% max was higher in healthy subjects aged 51-80 yrs than in those aged 18-50 yrs (11.4 \pm 3.4 versus $8.2 \pm 2.9 \%$, respectively). Observations in the healthy group were similar when peak EMGdi or CMAPdi,Ms were used to normalise EMGdi.

Levels of neural respiratory drive were higher in chronic obstructive pulmonary disease patients than healthy subjects, and related to disease severity. Diaphragm compound muscle action potential could be used to normalise diaphragm electromyogram if volitional inspiratory manoeuvres could not be performed, allowing translation of the technique to critically ill and ventilated patients.

KEYWORDS: Chronic obstructive pulmonary disease, electromyography, respiratory diaphragm

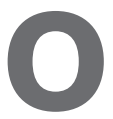
bjective markers of disease severity that reflect the physiological load on the respiratory system in chronic obstructive pulmonary disease (COPD) are currently lacking. Although COPD severity is categorised in terms of forced expiratory volume in one second (FEV1) in management guidelines [1], correlations between FEV1 and breathlessness [2] or quality of life are modest [3], and reported relationships between FEV1 and prognosis are inconsistent [46]. Two small studies confirm that neural respiratory drive (NRD) is increased in COPD [7] and relates to symptoms [8], but the use of measurements of NRD to assess disease severity in COPD has not been fully investigated, in part because there are no data to define ranges of NRD within the healthy population.

In COPD, mechanical abnormalities including airflow obstruction, static and dynamic hyperinflation and intrinsic positive end-expiratory pressure increase the load on the respiratory muscles. The translation of inspiratory muscle contraction into negative intrathoracic pressure, and of pressure changes to ventilation, is impaired as a consequence of muscle shortening, increased velocity of contraction, alteration in geometry and reduced compliance of the respiratory system. This results in high NRD in COPD, and disproportionate increases whenever airways obstruction worsens (and hyperinflation increases) or ventilatory requirements increase. The neural output of the brainstem respiratory centre cannot easily be measured directly in humans, but NRD can be assessed indirectly by quantifying the electromyogram (EMG) of the respiratory muscles, which provides a method of assessing the level and pattern of their activation [9]. The EMG of the diaphragm (EMGdi), the major inspiratory muscle during resting tidal breathing in healthy individuals, can be recorded specifically using oesophageal electrodes positioned at the diaphragm crus [10]. Multipair oesophageal electrode catheters have been

\section{AFFILIATIONS}

*King's College London School of Medicine, King's College Hospital 'Royal Brompton Hospital, London, UK,

\# Guangzhou Institute of Respiratory Diseases, Guangzhou Medical College, State Key Laboratory of Respiratory Disease, Guangzhou, China.

CORRESPONDENCE

C.J. Jolley

Dept of Asthma

Allergy and Respiratory Science

King's College London School of

Medicine

King's College Hospital

Bessemer Road

London SE5 9PJ

UK

Fax: 442032993589

E-mail: caroline.jolley@kcl.ac.uk

Received:

June 192008

Accepted after revision:

September 252008

\section{SUPPORT STATEMENT}

C.J. Jolley is supported by a Medical Research Council (London, UK)

Clinical Research Training

Fellowship. C.J. Jolley and Y-M. Luo hold British Council (Manchester,

UK) Researcher Exchange

Programme Awards. The

collaboration between King's College

London and Guangzhou Institute of

Respiratory Disease is supported by a

Royal Society (London) International

Joint Project Grant.

STATEMENT OF INTEREST

None declared. 
developed and used to measure NRD [11-14]. Using these electrodes, SINDERBY et al. [7] have shown that the amplitude of EMGdi is higher in patients with significant respiratory disease than in healthy subjects, when normalised to each subject's volitional maximum (EMGdi \% max). However, the number of subjects in the study was small (five healthy males, five COPD patients and five post-polio infection), and it was not designed to explore the use of EMGdi \% max as a marker of disease severity.

The main aims of the present study were to use the EMGdi to measure NRD in a large cohort of healthy subjects for comparison with levels of NRD in COPD patients, and to investigate the relationship between NRD and pulmonary function in COPD. It was hypothesised that resting EMGdi \% max would be significantly higher in COPD patients than in healthy subjects, and that resting EMGdi \% max would be highest in COPD patients with the most severe disease. A further aim was to test the hypothesis that there is a positive correlation between the amplitude of the diaphragm compound muscle action potential recorded following bilateral anterolateral magnetic stimulation (CMAPdi,MS) and the peak root mean square of spontaneous EMGdi activity (RMSEMGdi,peak) recorded during maximal volitional inspiratory manoeuvres. If so, normalising EMGdi to CMAPdi,MS could avoid the difficulties associated with the use of volitional tests of maximum diaphragm activation for normalisation in clinical situations where it is impossible to perform the necessary inspiratory manoeuvres. Assessing the load on the respiratory system by quantifying EMGdi nonvolitionally in this way could be particularly valuable in the critical care population, particularly in the assessment of the need for ventilatory support, where EMGdi \% max values could provide an index of ventilatory reserve. Indeed, calibration of the level of ventilatory support in response to levels of neural respiratory drive is the basis of novel neurally adjusted ventilatory assist (NAVA) technology currently in development [15].

\section{METHODS \\ Subjects}

In total, 100 healthy subjects (mean \pm SD age $40.3 \pm 17.4$ yrs (range 18-79 yrs); 56\% male; ethnicity: 54\% Chinese, 36\% white European, $10 \%$ other) and 30 COPD patients (age $66.6 \pm 7.82$ (52-88) yrs; $76.0 \%$ male; ethnicity: 63\% white European, 37\% Chinese; FEV1 $34.8 \pm 13.9 \%$ predicted) were studied. The subjects' age, height, weight and body mass index (BMI) were documented. Spirometry (FEV1 and slow vital capacity (VC)) and inspiratory capacity (IC) were also measured in COPD patients. Informed consent was taken and the study was performed in accordance with Local Research Ethics Committee (King's College Hospital, London, UK) procedures.

\section{Instrumentation and signal processing}

EMGdi recordings were made from the crural diaphragm using multipair oesophageal electrode catheters, as previously described [13]. Further details of the electrode design, positioning and signal processing are given in the online supplementary material.

\section{EMGdi recordings at rest and during maximal inspiratory manoeuvres}

Recordings were made sitting upright in a chair, with a noseclip in place for all measurements except sniff nasal pressure.
To record EMGdi during resting breathing, subjects sat quietly in a relaxed posture for $\geqslant 5 \mathrm{~min}$, until $\geqslant 2 \mathrm{~min}$ of stable, consistent EMGdi signals had been recorded. Airflow was measured through a mouthpiece connected in series to a pneumotachograph. EMGdi was then recorded during four inspiratory manoeuvres: 1) maximal inspiration to total lung capacity (TLC); 2) maximal static inspiratory effort at functional residual capacity (FRC) against a closed valve [16]; 3) maximal sniff from FRC; and 4) maximum voluntary ventilation for $15 \mathrm{~s}$ ("sprint MVV"). Manoeuvres 1-3 were repeated at least three times, until the investigator was satisfied that a truly maximum effort had been performed. The sprint MVV was performed once only.

\section{Calculation of resting EMGdi}

The raw signal was converted to root mean square (RMS; Powerlab Chart v5.4 software, ADInstruments, Chalgrove, UK), using a time constant of $50 \mathrm{~ms}$ and a moving window. The maximum RMS-EMGdi value during 100-ms subdivisions of each breath was then determined, manually selecting EMGdi signals falling between QRS complexes of the ECG artefact. The mean maximum RMS-EMGdi per breath over two representative 30-s subdivisions of the whole recording was then calculated.

\section{Calculation of EMGdi \% max}

EMGdi signals recorded during each of the maximum inspiratory manoeuvres were converted to RMS. The largest RMS-EMGdi value calculated by analysis of these recordings was labelled "RMS-EMGdi,peak". EMGdi \% max for each subject was then calculated as the mean maximum RMSEMGdi per breath as a percentage of RMS-EMGdi,peak.

\section{Assessment of intra- and interobserver reproducibility of EMGdi \% max}

In total, 10 healthy subjects were studied on two occasions $>24 \mathrm{~h}$ apart, at the same time of day. The intraobserver reproducibility of EMGdi \% max measurements was assessed by comparing the results of a single investigator's (C.J. Jolley) analysis of measurements made on two separate days. The interobserver reproducibility of EMGdi \% max measurements was assessed by comparing the results of two investigators' (C.J. Jolley and C. Reilly) analysis of a single set of measurements in five of these subjects.

\section{Bilateral anterolateral magnetic phrenic nerve stimulation}

Bilateral anterolateral magnetic phrenic nerve stimulation (BAMPS) was performed using two double circular 43-mm coils (P/N 9784-00; Magstim Co.,Whitland, UK) placed anterolaterally over the left and right phrenic nerves, as previously described [17]. The coils were powered by a Magstim 200 stimulator (Magstim Co.). During the study, subjects were seated upright in a chair with a nose-clip in place. Stimulation was performed at end-expiration with the abdomen unbound. BAMPS was performed at 80, 85, 90, 95 and $100 \%$ maximum stimulator output (MSO), to determine supramaximality. The amplitude of the CMAPdi,MS was measured as the peak-trough amplitude, as previously described [18]. The interoccasion coefficient of variation (CV) in the previous study was $8.6 \%$ [18]. 


\section{Statistical analysis}

Ranges of EMGdi \% max were expressed as 95\% confidence intervals of the mean. Comparisons between healthy and COPD subjects were made using independent sample t-tests except comparisons of sex distributions, which were made using Fisher's exact test. Values of $\mathrm{p}$ were considered to be significant at $<0.05$ level. Relationships between EMGdi and anthropometric or lung function variables were investigated by regression analysis. Intra- and interobserver reproducibility was assessed by calculating the $\mathrm{CV}$ and by Bland-Altman analysis [19].

\section{RESULTS}

Data are presented as mean \pm SD. Anthropometric and lung function data for both healthy subjects and COPD patients are summarised in table 1.

Representative traces at rest and during maximum voluntary ventilation in a healthy subject and a COPD patient are shown in figure 1. Comparisons of peak RMS-EMGdi values during the different manoeuvres are given in the online supplementary material.

\section{Healthy subjects}

The mean \pm SD EMGdi \% max of the healthy group was $9.0 \pm 3.4 \%$. The EMGdi \% max was $9.2 \pm 3.4 \%$ for males and $8.8 \pm 3.3 \%$ for females $(\mathrm{p}=0.53)$.

Correlations between EMGdi \% max and age, height, weight and BMI are shown in table 2. EMGdi \% max was slightly higher in healthy subjects aged $51-80$ yrs $(26 \%$ of the total healthy subjects, 13 male) than in those aged $18-50$ yrs ( $74 \%$ of the total, 43 male; $11.4 \pm 3.40$ versus $8.16 \pm 2.92 \%$, respectively; $\mathrm{p}=0.001)$, although the overall linear correlation between EMGdi \% max and age was weak $(r=0.34$, $p<0.001$; see online supplementary material). There was no significant difference in RMS-EMGdi,peak between the older and younger cohorts $(226.4 \pm 71.7$ versus $250.3 \pm 67.4 \mu \mathrm{V}$, respectively). There were weak but significant negative correlations between EMGdi \% max and absolute FEV1 $(\mathrm{r}=-0.34, \mathrm{p}=0.001)$, and between EMGdi \% max and absolute VC $(r=-0.21, p=0.04)$.

\begin{tabular}{|c|c|c|c|}
\hline \multirow[t]{2}{*}{ TABLE 1} & \multicolumn{3}{|c|}{$\begin{array}{l}\text { Demographic and anthropometric data for all } \\
\text { healthy subjects and chronic obstructive } \\
\text { pulmonary disease (COPD) patients }\end{array}$} \\
\hline & Healthy & COPD & $p$-value \\
\hline Subjects $n$ & 100 & 30 & \\
\hline Age yrs & $40.0 \pm 17.4$ & $66.6 \pm 7.82$ & $<0.001$ \\
\hline Height $\mathrm{m}$ & $1.65 \pm 0.08$ & $1.67 \pm 0.08$ & 0.29 \\
\hline Weight kg & $62.9 \pm 12.1$ & $63.9 \pm 13.9$ & 0.75 \\
\hline $\mathrm{BMI} \mathbf{k g} \cdot \mathrm{m}^{-2}$ & $23.0 \pm 3.26$ & $23.0 \pm 4.39$ & 0.95 \\
\hline Male \% & 56.0 & 73.3 & 0.14 \\
\hline FEV $1 \%$ pred & $104.5 \pm 14.3$ & $34.8 \pm 13.9$ & \\
\hline VC \% pred & $106.4 \pm 13.4$ & $83.0 \pm 18.6$ & \\
\hline
\end{tabular}

Data are presented as mean \pm SD, unless otherwise stated. BMI: body mass index; FEV1: forced expiratory volume in one second; \% pred: \% predicted; VC: vital capacity.
These data gave $95 \%$ confidence intervals of EMGdi \% max of $7.5-8.8 \%$ in normal subjects aged $18-50 \mathrm{yrs}$, and $10.1-12.8 \%$ in subjects aged $>50$ yrs.

Sniff nasal inspiratory pressure (SNIP) was higher in the subjects aged $18-50$ yrs than in those aged $51-80$ yrs $\left(91.4 \pm 22.3\right.$ versus $80.5 \pm 16.3 \mathrm{cmH}_{2} \mathrm{O}$, respectively; $\left.\mathrm{p}=0.04\right)$, but the relationship between EMGdi \% max and SNIP values was weak $(r=0.19, p=0.06 ; n=98)$. The difference between maximal inspiratory pressure $(P I, \max )$ in those aged $18-50$ yrs and those aged 51-80 yrs approached statistical significance $\left(80.6 \pm 32.6\right.$ versus $69.5 \pm 20.7 \mathrm{cmH}_{2} \mathrm{O}$, respectively; $\left.\mathrm{p}=0.09\right)$. There was no significant relationship between EMGdi \% max and $P \mathrm{I}, \max (\mathrm{r}=0.10, \mathrm{p}=0.31)$.

Correlations between EMGdi \% max and age, height, weight and BMI were similar in the white European and Chinese subgroups. Data comparing EMGdi \% max values in white European and Chinese ethnic groups are provided in the online supplementary material.

\section{CMAPdi,MS}

CMAPdi,MS was assessed in 64 subjects. Supramaximality was judged to have been achieved when the mean CMAPdi,MS amplitude at $100 \%$ MSO was less than $5 \%$ greater than the highest mean CMAPdi,MS amplitude achieved at the lower stimulator outputs. Using these criteria, supramaximality was achieved in $92.8 \%$ of the subjects. The CMAPdi,MS amplitude achieved at $100 \%$ MSO values was recorded if supramaximality was not achieved.

Representative traces recorded during BAMPS are shown in the online supplementary material. The mean \pm SD CMAPdi,MS amplitude was $2.4 \pm 0.7 \mathrm{mV}$. The phrenic nerve conduction time (PNCT), defined as the time from the stimulation artefact to the onset of the CMAP, was $6.9 \pm 0.7 \mathrm{~ms}$.

\section{Relationships between CMAPdi,MS amplitude and RMS-EMGdi}

Linear regression analysis revealed a positive correlation between each subject's RMS-EMGdi,peak and CMAPdi,MS amplitude ( $\mathrm{r}=0.59, \mathrm{p}<0.001$; fig. 2 ). The mean \pm SD RMS-EMGdi per breath (in $\mu \mathrm{V}$ ) expressed as a percentage of CMAPdi,MS amplitude (RMS-EMGdi/CMAPdi,MS) was $0.9 \pm 0.4 \%$. The relationships between RMS-EMGdi/CMAPdi,MS and age, height, weight and BMI were similar to those with EMGdi \% $\max$ (table 2).

\section{COPD patients}

EMGdi \% max in the COPD patients was $27.9 \pm 9.9 \%$. This was significantly higher than EMGdi \% max recorded in the 26 healthy controls matched for age, height, weight and BMI $(11.4 \pm 3.4 \%$; $<<0.001$; table 3 and fig. 3$)$. COPD patients generated a smaller tidal volume $(V \mathrm{~T})$ as a percentage of the predicted VC (VCpred) per unit EMGdi \% max ((VT \% VCpred)/ (EMGdi \% max)) than the healthy controls $(0.8 \pm 0.4$ versus $1.4 \pm 0.6$ arbitrary units, respectively; table 3 and fig. 3 ).

All patients completed FEV1 and VC measurements, and IC was measured in 20 patients. Significant correlations, best described by curve regression functions, were observed between EMGdi \% max and FEV1 \% pred, VC \% pred and IC \% pred, and between (VT \% VCpred)/(EMGdi \% max) and FEV1 \% pred, VC \% pred 

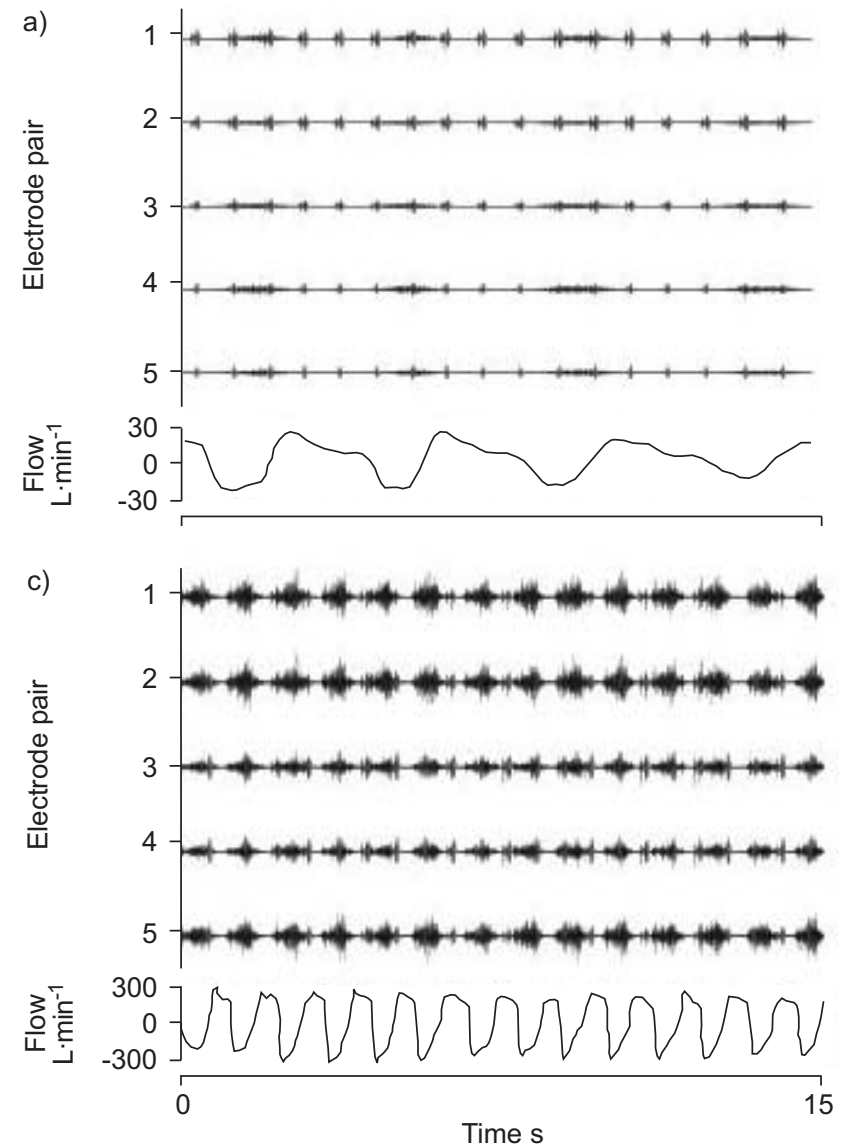

b)

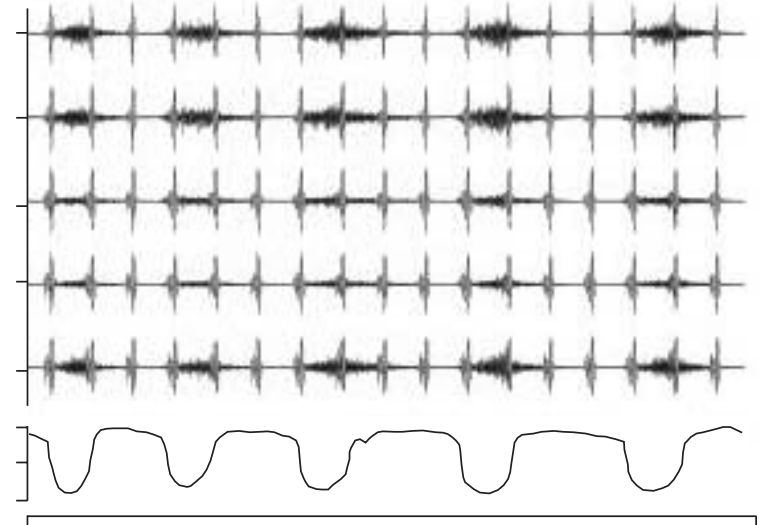

d)

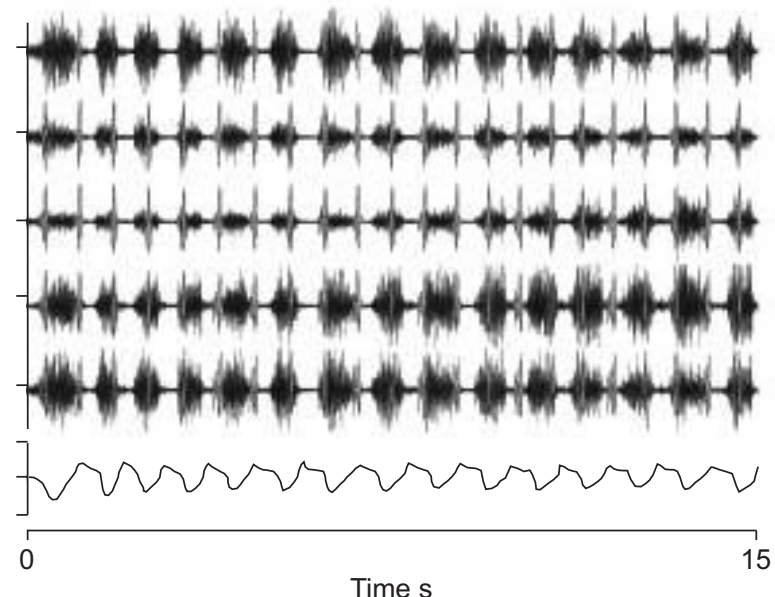

FIGURE 1. Representative traces at rest ( $a$ and $b$ ) and during maximum voluntary ventilation ( $c$ and $d$ ) in a healthy subject (a and $c$ ) and in a severe chronic obstructive pulmonary disease patient ( $b$ and $d)$. Diaphragm electromyogram traces recorded from electrode pairs 1 to 5 (distal to proximal) are shown. The scale of each electrode pair is +500 to $-500 \mu \mathrm{V}$. Flow is calibrated with inspiration as negative values.

and IC $\%$ pred (table 4 , fig. 4 and additional figures in the online supplementary material).

\section{Peak RMS-EMGdi values during different maximal inspiratory manoeuvres}

Data are presented as median (interquartile range (IQR)), as the sprint MVV data were non-normally distributed. The data are also presented in tables S2 and S3 and in figure S3, in the online supplementary material.

The TLC and PI,max manoeuvres yielded peak values most frequently in the healthy group ( $31 \%$ each), and the TLC manoeuvre yielded the highest RMS-EMGdi values on average in that group (median (IQR) 208.2 (98.7) $\mu \mathrm{V}$ ). The sniff manoeuvre yielded peak values most frequently in the COPD group (33\%) and yielded the highest RMS-EMGdi values on average in that group (170.6 (76.5) $\mu \mathrm{V})$. The MVV manoeuvre yielded the lowest values in both groups (healthy $158.7(78.4) \mu \mathrm{V}$, COPD $150.2(97.2) \mu \mathrm{V})$ despite yielding the highest value in $26 \%$ of the COPD group.

There were no significant differences between RMS-EMGdi values when the manoeuvres were compared for the COPD group (using the Wilcoxon signed-rank test to compare values

TABLE 2 Correlations between EMGdi \% max and RMS-EMGdi/CMAPdi,MS, and height, weight, BMl and age in healthy subjects

\begin{tabular}{|c|c|c|c|c|c|c|c|c|}
\hline & \multicolumn{2}{|c|}{ Height } & \multicolumn{2}{|c|}{ Weight } & \multicolumn{2}{|c|}{ BMI } & \multicolumn{2}{|c|}{ Age } \\
\hline & r-value & $\mathrm{p}$-value & r-value & $\mathrm{p}$-value & r-value & p-value & r-value & p-value \\
\hline EMGdi \% max & 0.002 & 0.62 & 0.09 & 0.39 & 0.12 & 0.24 & 0.34 & $<0.001$ \\
\hline RMS-EMGdi/CMAPdi,MS & -0.05 & 0.69 & 0.08 & 0.53 & 0.14 & 0.29 & 0.28 & 0.02 \\
\hline
\end{tabular}

EMGdi: diaphragm electromyogram; \% max: \% maximum; RMS: root mean square; CMAPdi,MS: amplitude of the diaphragm compound muscle action potential following bilateral anterolateral magnetic stimulation; BMI: body mass index. 


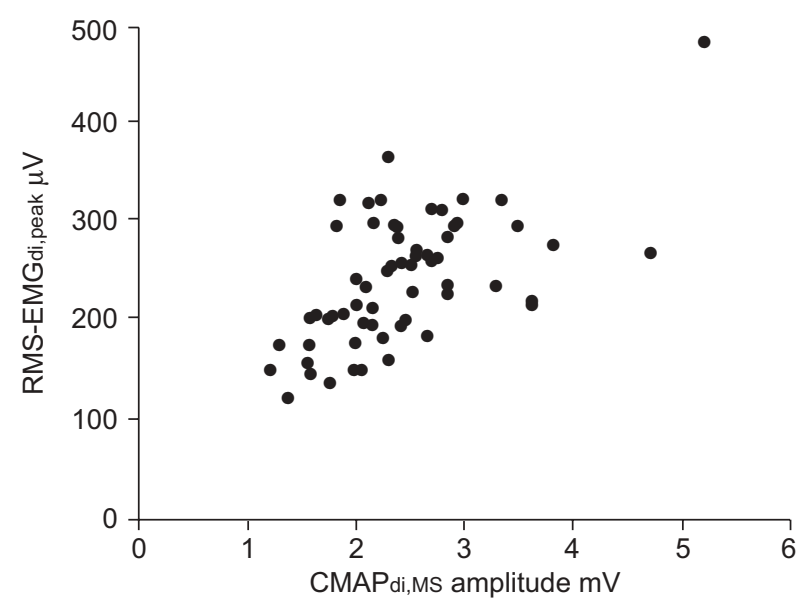

FIGURE 2. Relationship between amplitude of the diaphragm compound muscle action potential following bilateral anterolateral magnetic stimulation (CMAPdi,MS) and peak root mean square of spontaneous diaphragm electromyogram activity (RMS-EMGdi,peak). Linear regression analysis revealed a positive correlation between each subject's RMS-EMGdi,peak and CMAPdi,MS amplitude $(r=0.59, p<0.001)$

within the same subject). In the healthy group, significant differences were observed between all manoeuvres except sniff and $P I, \max (\mathrm{p}=0.62)$.

\section{Intrasubject and interobserver reproducibility of EMGdi \% max in healthy subjects}

Intrasubject reproducibility

The coefficient of repeatability between EMGdi \% max measurements made and analysed by the same investigator on two separate days, in 10 subjects, was 0.94 [19]. The mean \pm SD CV was $0.09 \pm 0.05$.

\section{Interobserver reproducibility}

The mean \pm SD CV of EMGdi \% max between measurements made in five subjects on the same day, comparing the results of analysis by two investigators, was $0.10 \pm 0.08$. The intraclass correlation coefficient was 0.71. Tables and Bland-Altman plots of these data are presented in the online supplementary material.

\section{DISCUSSION}

The present study is the first to define normal ranges of NRD as EMGdi \% max in a large population of healthy adults; the largest previous study included 15 participants [7]. In healthy subjects, levels of EMGdi \% max increased slightly with age, but there were no significant correlations between EMGdi \% max and sex, height, weight or BMI in this largely non-obese population.

EMGdi \% max was found to be significantly higher in the COPD group than in matched healthy subjects. The average EMGdi \% max in the current cohort of healthy subjects was $9.0 \pm 3.4 \%$ overall, which is of the same order as levels of EMGdi \% max described previously in a smaller study by SINDERBY et al. [7], who demonstrated resting values of $8.4 \pm 2.5 \%$ and $43.4 \pm 22.1 \%$ in five healthy and five severe COPD patients, respectively, using similar methods. The lower average EMGdi \% max found in the present COPD patients is

\begin{tabular}{|c|c|c|c|}
\hline \multirow[t]{2}{*}{ TABLE 3} & \multirow[b]{2}{*}{ Healthy } & \multirow[b]{2}{*}{ COPD } & \multirow[b]{2}{*}{ p-value } \\
\hline & & & \\
\hline Subjects $n$ & 26 & 30 & \\
\hline Age yrs & $64.8 \pm 7.4$ & $66.6 \pm 7.8$ & 0.41 \\
\hline Height $\mathrm{m}$ & $1.66 \pm 0.1$ & $1.66 \pm 0.08$ & 0.79 \\
\hline Weight kg & $69.0 \pm 13.0$ & $63.9 \pm 13.9$ & 0.15 \\
\hline$B M I \mathbf{k g} \cdot \mathrm{m}^{-2}$ & $24.9 \pm 3.3$ & $23.0 \pm 4.4$ & 0.06 \\
\hline Male \% & 50.0 & 73.3 & 0.10 \\
\hline FEV1 \% pred & $110.8 \pm 16.9$ & $34.8 \pm 13.9$ & $<0.001$ \\
\hline vc \% pred & $113.3 \pm 15.3$ & $83.0 \pm 18.6$ & $<0.001$ \\
\hline$V_{T} \mathbf{m L}$ & $499.3 \pm 167.4$ & $608.3 \pm 199.4$ & 0.03 \\
\hline VT \% VCpred & $14.5 \pm 4.0$ & $18.7 \pm 5.6$ & 0.002 \\
\hline Tidal RMS-EMGdi per breath $\mu \mathrm{V}$ & $24.8 \pm 9.4$ & $53.2 \pm 29.0$ & $<0.001$ \\
\hline RMS-EMGdi,peak $\mu$ V & $226.4 \pm 71.7$ & $188.9 \pm 68.8$ & 0.052 \\
\hline EMGdi \% max & $11.4 \pm 3.4$ & $27.9 \pm 9.9$ & $<0.001$ \\
\hline (VT \% VCpred)/(EMGdi \% max) AU & $1.4 \pm 0.6$ & $0.8 \pm 0.4$ & $<0.001$ \\
\hline \multicolumn{4}{|c|}{$\begin{array}{l}\text { Data are presented as mean } \pm \mathrm{SD} \text {, unless otherwise stated. EMGdi: diaphragm } \\
\text { electromyogram; \% max: \% maximum; COPD: chronic obstructive pulmonary } \\
\text { disease; BMI: body mass index; FEV1: forced expiratory volume in one second; } \\
\% \text { pred: \% predicted; VC: vital capacity; } V \mathrm{~T} \text { : tidal volume; \% VCpred: percentage } \\
\text { of predicted VC; RMS: root mean square; RMS-EMGdi,peak: peak RMS of } \\
\text { spontaneous EMGdi activity; AU: arbitrary units. }\end{array}$} \\
\hline
\end{tabular}

likely to reflect the range of disease severity. By showing that there is a correlation between EMGdi \% max and the degree of airflow obstruction and hyperinflation, and that this is a reproducible measure, the present study builds on earlier observations and demonstrates the potential value of EMGdi \% max as an objective marker of disease severity in COPD.

\section{Determinants of EMGdi \% max}

In general, levels of NRD increase when the load on the respiratory muscles increases relative to their capacity, i.e. if the load increases, the capacity of the muscles decreases, or a combination of these two changes. Levels of EMGdi \% max can therefore be explained in terms of ventilatory mechanics, and the pathophysiological changes in ventilatory mechanics that occur with disease.

\section{Healthy subjects}

An average EMGdi \% max of 9.0\% in normal subjects, in whom it can be assumed that there is no neuromechanical dissociation, is consistent with the high levels of ventilatory reserve that are known to exist in healthy individuals. The slightly increased EMGdi \% max observed in the older (51-80 yrs of age) cohort compared with that of subjects aged $<50$ yrs is likely to reflect the known "normal" changes in ventilatory mechanics occurring with increased age. Declines in FEV1 [20], VC [21], respiratory muscle strength [22] and chest wall compliance [23] observed during healthy ageing all increase the load:capacity ratio of the respiratory muscle pump, reducing ventilatory reserve, and would explain the tendency to higher levels of EMGdi \% max in the older age group. The findings of significant negative correlations between EMGdi \% max and absolute FEV1 


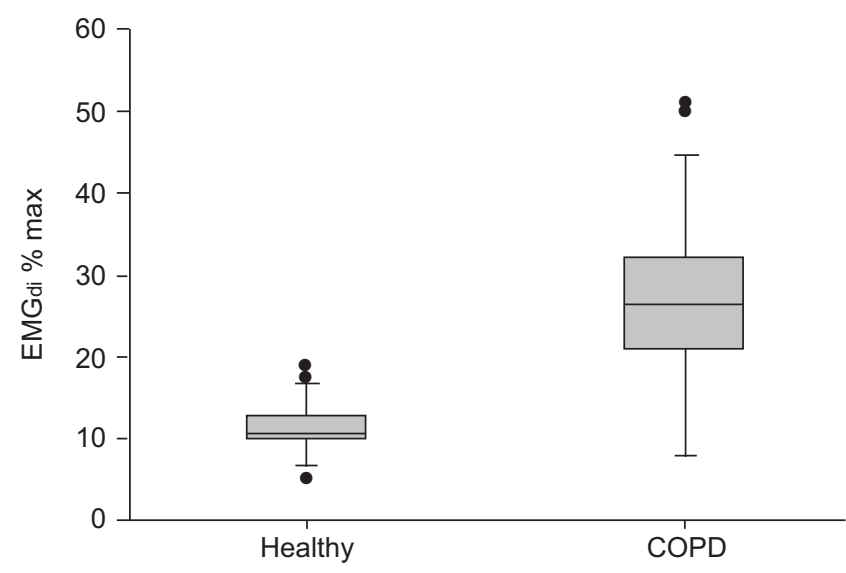

FIGURE 3. Box-and-whisker plots comparing diaphragm electromyogram as a percentage of maximum (EMGdi \% max) in 30 chronic obstructive pulmonary disease (COPD) patients with 26 healthy subjects matched for age, height, weight and body mass index. Comparisons are made using the independent samples ttest. The box length is the interquartile range. $\bullet$ : outliers, i.e. cases with values between 1.5 and 3 interquartile ranges from the upper or lower edge of the box.

and VC are consistent with this. The current observation that the correlation of SNIP and PI,max with EMGdi \% max is weak suggests that altered lung and chest wall mechanics are more important contributors to increased drive than reduced diaphragm contractility in the healthy older cohort.

\section{COPD}

The results of the present study confirm the hypotheses that EMGdi \% max would be higher in COPD patients than healthy subjects, and that the levels of EMGdi \% max would be highest in patients with the most severe disease. High levels of EMGdi $\%$ max indicate that there is a relative increase in the RMS of EMGdi in COPD compared with healthy subjects, i.e. recruitment of larger numbers of diaphragm motor units and/or an increase in diaphragm motor unit firing rate in COPD. It is, in fact, well known that the firing frequency of motor neurons supplying both the diaphragm [24] and nondiaphragmatic muscles [25] is increased in COPD. However, DE TROYER et al. [24] and GANDEVIA et al. [25] used needle electrodes, which is clearly not feasible in general clinical practice.

The increase in the RMS of EMGdi in COPD is likely to be the result of three main factors. First, the diaphragm must generate more pressure to achieve a given $V \mathrm{~T}$, compared with healthy subjects. Increased airways resistance in COPD results in significant expiratory airflow limitation at rest, leading to gas trapping, which increases intrathoracic end-expiratory pressure. A positive end-expiratory pressure imposes a threshold load that must be overcome before inspiratory airflow can be generated. A reduction in chest wall compliance, as hyperinflation progresses, also contributes to the mechanical load associated with inspiration in severe disease. Hyperinflation is also due to a loss of elastic recoil in emphysema. Secondly, the maximum pressuregenerating capacity of the diaphragm is reduced. POLKEY et al. [26] demonstrated a linear negative correlation of twitch transdiaphragmatic pressure with increasing lung volume of $3.5 \mathrm{cmH}_{2} \mathrm{O} \cdot \mathrm{L}^{-1}$. The ability of the diaphragm to generate

\begin{tabular}{|c|c|c|c|c|c|c|c|}
\hline \multirow[t]{3}{*}{ TABLE 4} & \multicolumn{7}{|c|}{$\begin{array}{l}\text { Correlations between EMGdi \% max and (VT \% } \\
\text { VCpred)/(EMGdi \% max) and \% predicted FEV1, } \\
\text { VC and IC }\end{array}$} \\
\hline & & \multicolumn{2}{|c|}{ FEV $_{1} \%$ pred } & \multicolumn{2}{|c|}{ VC \% pred } & \multicolumn{2}{|c|}{ IC \% pred } \\
\hline & & $r^{2}$ & p-value & $r^{2}$ & p-value & $r^{2}$ & p-value \\
\hline \multirow{2}{*}{\multicolumn{2}{|c|}{$\begin{array}{l}\text { EMGdi \% max } \\
(\text { VT \% VCpred)/ } \\
\text { (EMGdi \% max) }\end{array}$}} & 0.40 & $<0.001$ & 0.61 & $<0.001$ & 0.28 & 0.02 \\
\hline & & 0.25 & 0.005 & 0.48 & $<0.001$ & 0.36 & 0.006 \\
\hline \multicolumn{8}{|c|}{$\begin{array}{l}\text { EMGdi: diaphragm electromyogram; \% max: \% maximum; VT: tidal volume; VC: } \\
\text { vital capacity; \% VCpred: percentage of predicted VC; FEV1: forced expiratory } \\
\text { volume in one second; IC: inspiratory capacity; \% pred: \% predicted. }\end{array}$} \\
\hline
\end{tabular}

transdiaphragmatic and oesophageal pressure is, therefore, reduced in COPD, and these changes are exaggerated with acute-on-chronic hyperinflation. Thirdly, patients with COPD need to generate increased absolute levels of ventilation to overcome ventilation/perfusion $\left(V^{\prime} / Q^{\prime}\right)$ mismatch [27].

Although RMS-EMGdi,peak in COPD patients was 83\% lower than in healthy subjects, a lower denominator is unlikely to explain the higher EMGdi \% max in COPD, as correcting for this gives an average EMGdi \% max in COPD of $23.5 \pm 8.2 \%$, still significantly higher than EMGdi \% max in the healthy group $(\mathrm{p}<0.001)$.

\section{Significance of raised EMGdi \% max and reduced (VT \% VCpred)/(EMGdi \% max) in COPD}

The current finding that EMGdi \% max is raised, and is negatively correlated with FEV1, VC and the degree of hyperinflation at rest (described in terms of IC \% pred) in COPD, reinforces the contention that, by providing a composite measure of ventilatory load and capacity, EMGdi \% max could provide an alternative method of assessing COPD disease severity. This could be the focus of future studies in larger numbers of COPD patients, including a more detailed investigation of the relationship between EMGdi \% max and other physiological measures, including hypoxaemia, hypercapnia and $V^{\prime} / Q^{\prime}$ mismatch, than were carried out in the present study.

(VT \% VCpred)/(EMGdi \% max) was lower in COPD patients than healthy subjects, reflecting neuromechanical uncoupling in COPD, and this correlated with disease severity. Neuromechanical dissociation has previously been demonstrated during exercise in COPD using EMGdi measurements [28], but the relationship with disease severity has not previously been documented. This observation also emphasises the value of EMGdi \% max over other commonly used indirect measures of ventilatory drive, such as mouth occlusion pressure at $100 \mathrm{~ms}$ $\left(P_{0.1)}\right.$, or the amplitude of tidal oesophageal pressure swings, which will underestimate levels of NRD in COPD patients with the most neuromechanical dissociation.

\section{Bilateral CMAPdi,MS values}

To the best of the current authors' knowledge, there have been no previous studies that have compared CMAPdi,MS and RMS-EMGdi,peak in healthy subjects. Normal ranges of bilateral 

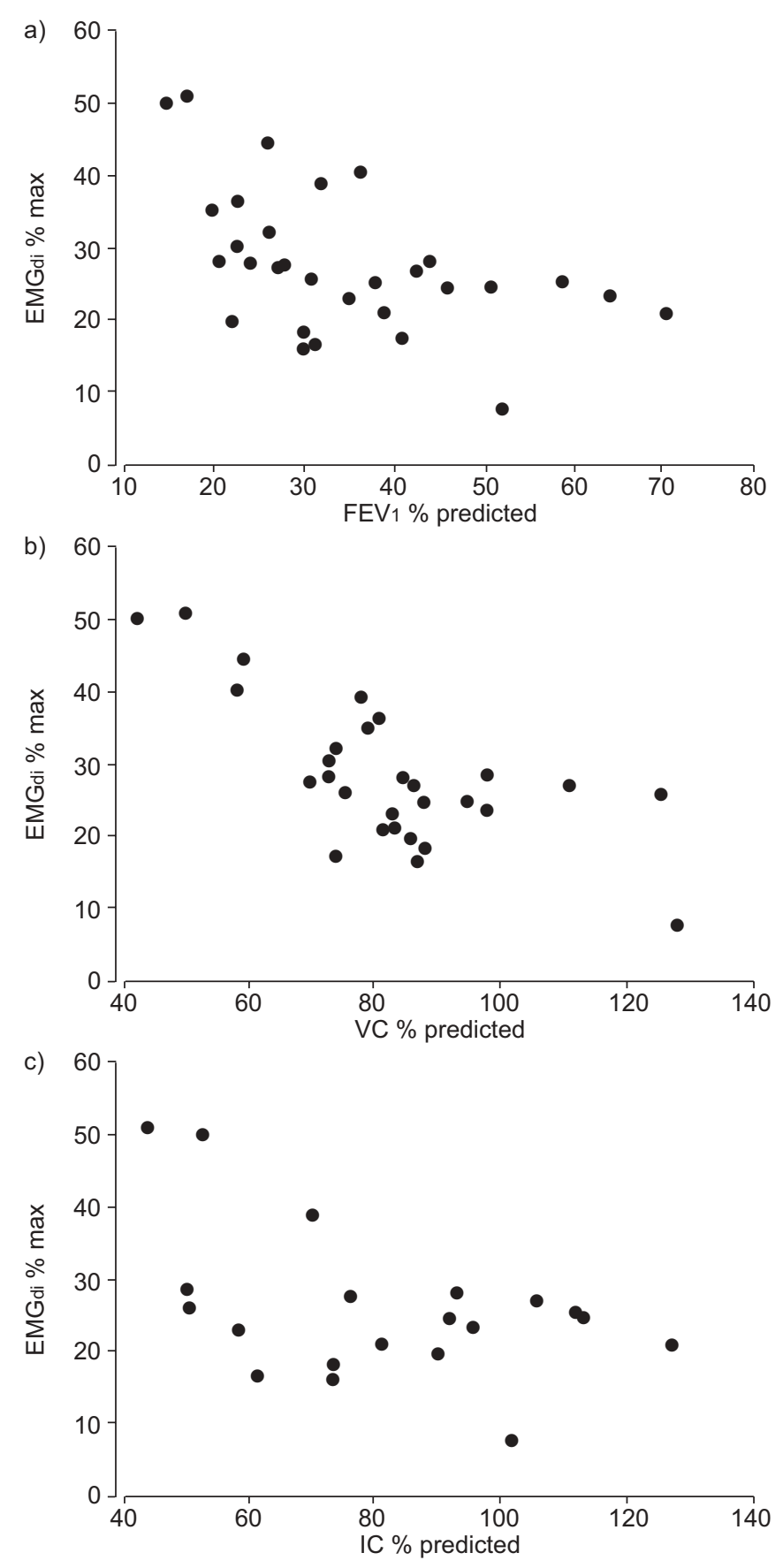

FIGURE 4. Scatter plots showing correlations between diaphragm electromyogram as a percentage of maximum (EMGdi \% max) and percentage predicted a) forced expiratory volume in one second (FEV1), b) vital capacity (VC) and c) inspiratory capacity $(I C)$, using curve estimation models. Regression coefficients $\left(r^{2}\right.$ values) and $p$-values were as follows: a) $r^{2}=0.40, p<0.001$; b) $r^{2}=0.61, p<0.001$; c) $r^{2}=0.28, p=0.02$

CMAPdi amplitudes and PNCT, recorded using an oesophageal electrode catheter following BAMPS, have also not previously been reported, principally because each phrenic nerve is usually assessed separately. The present findings of a mean \pm SD CMAPdi,MS amplitude of $2.4 \pm 0.7 \mathrm{mV}$ and a PNCT of $6.9 \pm 0.7 \mathrm{~ms}$ are consistent, following extrapolation from bito unilateral measurements, with a unilateral CMAPdi,MS amplitude and PNCT of $1.45 \pm 0.35$ and $6.9 \pm 0.9 \mathrm{~ms}$ (right) and $1.68 \pm 0.47$ and $7.6 \pm 0.7 \mathrm{~ms}$ (left), as previously recorded in a similar manner [18].

\section{Potential use of CMAPdi,MS amplitude to normalise EMGdi values}

The finding that there are relationships between the amplitude of the volitional and nonvolitional EMGdi in healthy subjects suggests that the nonvolitional signal (CMAPdi,MS amplitude) may be used in place of the volitional RMS-EMGdi,peak when normalising resting EMGdi to maximum. This could be of particular importance during the assessment of patients on intensive care units (ICUs), who are unable to generate maximal volitional inspiratory efforts. Potential applications include prediction of weaning failure in patients with respiratory muscle load:capacity imbalance sufficient to impact critically on ventilatory reserve. Levels of EMGdi \% max above the normal range would indicate that NRD had increased in response to an increase in ventilatory load with respect to the capacity of the respiratory muscles. Conversely, reductions in NRD, measured by assessing $P_{0.1}$, have been shown to be predictive of extubation failure on paediatric ICU [29]. P0.1 would, however, underestimate NRD in patients with disordered ventilatory mechanics, such as in COPD, where neuromechanical dissociation progresses exponentially as airflow obstruction and hyperinflation worsen [28]. This approach would also allow the level of EMGdi activity at which neural-assist ventilators such as NAVA [15] are triggered to be defined as EMGdi \% max, hence defining this threshold in terms of ventilatory reserve. Since ventilatory failure is the outcome of a critically low ventilatory reserve, this could prove to be a more appropriate approach than increasing NAVA support in response to changes from baseline EMGdi activity.

\section{Potential clinical applications of EMGdi measurements to quantify NRD}

The current study technique could be usefully applied to measure disease severity, progression and responses to treatment, in any disorder characterised by increased ventilatory load (e.g. airflow obstruction in asthma and COPD, reduced lung compliance in pulmonary fibrosis, or cardiac failure), reduced ventilatory capacity (in neuromuscular disease), or where there is a combination of both factors, such as in COPD, as herein discussed. The value of the method over other objective physiological measurements of disease severity, such as spirometry, or measurement of lung volumes, is that recording EMGdi gives a breath-by- breath measure of the load on the respiratory system, and can be used to provide measurements continuously during sleep without waking the patient [30], during exercise [28], and, as mentioned in the aforegoing discussion, could in addition be measured nonvolitionally in ventilated patients. The main factor limiting the translation of the technique to clinical practice is the acceptability of the oesophageal catheters to patients. However, in the current authors' experience of the use of these and similar catheters to assess intrathoracic pressure in clinical practice, the catheters are acceptable in $>95 \%$ of patients and are usually well tolerated.

In conclusion, the present study has demonstrated, in a large cohort of healthy subjects and patients with chronic obstructive 
pulmonary disease, that levels of neural respiratory drive, measured as diaphragm electromyogram as a percentage of maximum, are higher in patients with chronic obstructive pulmonary disease than in healthy subjects, and highest in patients with the most severe airflow obstruction and hyperinflation. Diaphragm electromyogram as a percentage of maximum therefore provides a composite measure of ventilatory load and capacity, and could provide a method of assessing chronic obstructive pulmonary disease severity. Normal ranges of diaphragm electromyogram as a percentage of maximum have also been established, which may be used for comparative data in future studies in patients with chronic obstructive pulmonary disease, or indeed any other cardiorespiratory disease, to further understanding of the pathophysiology of ventilatory failure. The current findings also demonstrate that nonvolitional activation of the diaphragm is of potential use in the assessment of diaphragm electromyogram as a percentage of maximum in patients who are unable to perform maximal volitional inspiratory manoeuvres.

\section{ACKNOWLEDGEMENTS}

The authors wish to thank the staff working in the Chest Unit, King's College Hospital (London, UK) for making the lung function measurements, and the Masters students in the Respiratory Muscle Unit of the Guangzhou Institute of Respiratory Diseases (Guangzhou, China), for their invaluable assistance during the studies carried out in Guangzhou.

\section{REFERENCES}

1 National Collaborating Centre for Chronic Conditions, Chronic obstructive pulmonary disease. Management of chronic obstructive pulmonary disease in adults in primary and secondary care. Available from www.nice.org.uk/CG012niceguideline. London, National Institute for Clinical Excellence, 2004..

2 Bestall JC, Paul EA, Garrod R, Garnham R, Jones PW, Wedzicha JA. Usefulness of the Medical Research Council (MRC) dyspnoea scale as a measure of disability in patients with chronic obstructive pulmonary disease. Thorax 1999; 54: 581-586.

3 Jones PW. Health status measurement in chronic obstructive pulmonary disease. Thorax 2001; 56: 880-887.

4 Postma DS, Burema J, Gimeno F, et al. Prognosis in severe chronic obstructive pulmonary disease. Am Rev Respir Dis 1979; 119: 357-367.

5 Martinez FJ, Foster G, Curtis JL, et al. Predictors of mortality in patients with emphysema and severe airflow obstruction. Am J Respir Crit Care Med 2006; 173: 1326-1334.

6 Hansen EF, Phanareth K, Laursen LC, Kok-Jensen A, Dirksen A. Reversible and irreversible airflow obstruction as predictor of overall mortality in asthma and chronic obstructive pulmonary disease. Am J Respir Crit Care Med 1999; 159: 1267-1271.

7 Sinderby C, Beck J, Spahija J, Weinberg J, Grassino A. Voluntary activation of the human diaphragm in health and disease. J Appl Physiol 1998; 85: 2146-2158.

8 Druz WS, Sharp JT. Electrical and mechanical activity of the diaphragm accompanying body position in severe chronic obstructive pulmonary disease. Am Rev Respir Dis 1982; 125: 275-280.
9 American Thoracic Society/European Respiratory Society, ATS/ERS Statement on respiratory muscle testing. Am J Respir Crit Care Med 2002; 166: 518-624.

10 Petit JM, Milic-Emili G, Delhez L. Role of the diaphragm in breathing in conscious normal man: an electromyographic study. J Appl Physiol 1960; 15: 1101-1106.

11 Sinderby CA, Beck JC, Lindström LH, Grassino AE. Enhancement of signal quality in esophageal recordings of diaphragm EMG. J Appl Physiol 1997; 82: 1370-1377.

12 Beck J, Sinderby C, Lindström L, Grassino A. Influence of bipolar esophageal electrode positioning on measurements of human crural diaphragm electromyogram. J Appl Physiol 1996; 81: 1434-1449.

13 Luo YM, Moxham J. Measurement of neural respiratory drive in patients with COPD. Respir Physiol Neurobiol 2005; 146: 165-174.

14 Luo YM, Hart N, Mustfa N, Lyall RA, Polkey MI, Moxham J. Effect of diaphragm fatigue on neural respiratory drive. J Appl Physiol 2001; 90: 1691-1699.

15 Sinderby C, Beck J, Spahija J, et al. Inspiratory muscle unloading by neurally adjusted ventilatory assist during maximal inspiratory efforts in healthy subjects. Chest 2007; 131: 711-717.

16 Black LF, Hyatt RE. Maximal respiratory pressures: normal values and relationship to age and sex. Am Rev Respir Dis 1969; 99: 696-702.

17 Mills GH, Kyroussis D, Hamnegard CH, Polkey MI, Green M, Moxham J. Bilateral magnetic stimulation of the phrenic nerves from an anterolateral approach. Am J Respir Crit Care Med 1996; 154: 1099-1105.

18 Luo YM, Lyall RA, Harris ML, Rafferty GF, Polkey MI, Moxham J. Quantification of the esophageal diaphragm electromyogram with magnetic phrenic nerve stimulation. Am J Respir Crit Care Med 1999; 160: 1629-1634.

19 Bland JM, Altman DG. Statistical methods for assessing agreement between two methods of clinical measurement. Lancet 1986; 1: 307-310.

20 Fowler RW, Pluck RA, Hetzel MR. Maximal expiratory flow-volume curves in Londoners aged 60 years and over. Thorax 1987; 42: 173-182.

21 Dockery DW, Ware JH, Ferris BG Jr, et al. Distribution of forced expiratory volume in one second and forced vital capacity in healthy, white, adult never-smokers in six U.S. cities. Am Rev Respir Dis 1985; 131: 511-520.

22 Polkey MI, Harris ML, Hughes PD, et al. The contractile properties of the elderly human diaphragm. Am J Respir Crit Care Med 1997; 155: 1560-1564.

23 Mittman C, Edelman NH, Norris AH, Shock NW. Relationship between chest wall and pulmonary compliance and age. J Appl Physiol 1965; 20: 1211-1216.

24 De Troyer A, Leeper JB, McKenzie DK, Gandevia SC. Neural drive to the diaphragm in patients with severe COPD. Am J Respir Crit Care Med 1997; 155: 1335-1340.

25 Gandevia SC, Leeper JB, McKenzie DK, De Troyer A. Discharge frequencies of parasternal intercostal and scalene motor units during breathing in normal and COPD subjects. Am J Respir Crit Care Med 1996; 153: 622-628.

26 Polkey MI, Kyroussis D, Hamnegard CH, Mills GH, Green M, Moxham J. Diaphragm strength in chronic obstructive pulmonary disease. Am J Respir Crit Care Med 1996; 154: 1310-1317. 
27 Wagner PD, Dantzker DR, Dueck R, Clausen JL, West JB. Ventilation-perfusion inequality in chronic obstructive pulmonary disease. J Clin Invest 1977; 59: 203-216.

28 Sinderby C, Spahija J, Beck J, et al. Diaphragm activation during exercise in chronic obstructive pulmonary disease. Am J Respir Crit Care Med 2001; 163: 1637-1641.
29 Manczur TI, Greenough A, Pryor D, Rafferty GF. Assessment of respiratory drive and muscle function in the pediatric intensive care unit and prediction of extubation failure. Pediatr Crit Care Med 2000; 1: 124-126.

30 Luo YM, Wu HD, Tang J, et al. Neural respiratory drive during apnoeic events in obstructive sleep apnoea. Eur Respir J 2008; 31: 650-657. 